\title{
Management : Adnexal mass in pregnant women
}

\section{RAMA JOSHI}

Management of adnexal mass in a pregnant woman presents a challenge as there is concern regarding the maternal as well as foetal outcome . Despite the rarity of malignancy the diagnosis of ovarian mass during pregnancy raises certain important issues like how quickly and efficiently the likelyhood of malignancy be determined ? Decision of elective operative intervention or postponement as well as the optimal time of surgical intervention!

With the widespread use of routine abdominal ultrasound examination during pregnancy, adnexal masses are observed with increasing frequency and are detected in 1-2\% of pregnancies. $(1,2,3)$ The common adenaxal masses diagnosed during pregnancy are -Functional Cysts, Benign Neoplasm or malignant ovarian tumours .Functional cysts are clear cysts of $<5 \mathrm{~cm}$ size and asymptomatic at presentation but have been documented as large as $10 \mathrm{~cm}$ size. Most of these functional cysts detected during early pregnancy disappear during the first 16 weeks of pregnancy and present no risk to the pregnancy. The persistent masses are pathological ,majority being of benign nature of which cystadenoma and benign cystic teratoma are common. $7 \%$ of diagnosed adenexal masses during pregnancy are malignant(3) with reported incidence of $1 / 8000$ to $1 / 20,000$ deliveries (4).

Careful evaluation of adnexal masses during pregnancy is required to determine the nature of the mass $(5,6)$. Ultrasonography and coloured doppler with Tumour markers help to differentiate benign from malignant. Interpretation of tumour markers is done with caution in pregnant patients. The CA 125 levels have been reported elevated in pregnancy especially in the first trimester \& during delivery(7). Elevated levels of AFP have been observed in pregnan-

Department of Gynacologic Oncology, Dharmshila Cancer Hospital, New Delhi

E-mail : joshi.rama@hotmail.com cies carrying fetus with Neural tube defects though LDH levels have not been affected by pregnancy.

The need for surgical intervention is considered in the following conditions when :

․ Malignancy is suspected.

口 An acute complication develops because of tortion, rupture or haemorrhage.

口 The sheer size of the tumour is likely to cause rupture or obstructed labour.

Surgery of adnexal mass during pregnancy increases the risk of abortion and preterm deliveries and IUGR. Some recent data suggest that adnexal surgery during the late second or early third trimester poses the greatest risk of preterm delivery or IUGR, or both (8). The time window of early to mid second trimester of pregnancy has been associated with a lower risk of pregnancy complications with elective surgery for an adnexal mass.

Frequently observed ovarian malignancies in association with pregnancy are Epithelial Ovarian cancer in $35 \%$ which are commonly low malignant potential tumours. Germ cell tumours in $33 \%$, dysgerminoma being the commonest in $30 \%$, Gonadal Stromal tumours in $20 \%$.(9)

Most of ovarian malignancies diagnosed during pregnancy are stage I thus have favourable prognosis (10). Surgical management is similar to that in nonpregnant patient. In these patients intraoperative frozen section analysis is essential for appropriate intraoperative decisions. In patients presenting as stage I, the unilateral salpingo oophorectomy with appropriate staging is the recommended procedure. The extent of the surgery in advanced stage of the disease will depend on the gestational age and foetal viability. The limited data on laparoscopy during the first and early second trimesters of pregnancy indicate that it is as safe as laparotomy 
(11).

Pregnant and nonpregnant women with stage 1A or $1 \mathrm{C}$ epithelial ovarian cancer who undergo fertility-preserving surgery (with chemotherapy in selected patients) have a good prognosis and a high likelihood of achieving a subsequent normal pregnancy(12) The same is true for women with a malignant germ-cell tumour of the ovary, even when disease is advanced(13). The indications of chemotherapy are similar to that in nonpregnant patients. All patients of germ cell tumour other than dysgerminoma stage IA and Immature teratoma stage IA Grade I should receive chemotherapy. Successful outcome of both mother and the infant have been reported in several published case reports when chemotherapy of Bleomycin, Etoposide and Cisplatinum or vinblastin, cisplatin and Bleomycin (14)were received by the mother in second or third trimester of pregnancy. There have also been several case reports documenting safe administration of cyclophosphamide, Cisplatinum or carboplatinum and carboplatinum and paclitaxel in second and third trimester of pregnancy for epithelial ovarian cancer $(15,16)$.

Clearly, an informed discussion of the options with the patient is imperative before any surgery, or chemotherapy is planned and any treatment delay should be carefully considered. Pregnancy does not appear to alter the prognosis for the patient with an ovarian malignancy, and ovarian cancer has not been reported to metastasize to the fetus.

\section{REFERENCES :}

1. Bernhard LM, Klebba PK, Gray DL, Mutch DG. Predictors of persistence of adnexal masses in preg. nancy. Obstet Gynecol. 1999; 93: 585 -589.

2. Platek DN, Henderson CE, Goldberg GL. The management of a persistent adnexal mass in pregnancy. Am J Obstet Gynecol. 1995; 173: 1236 -1240.

3. Bromley B, Benacerraf B. Adnexal masses during pregnancy: accuracy of sonographic diagnosis and outcome. J Ultrasound Med. 1997; 16: 447 -452.

Roberts JA. Management of gynaecologic tumours during pregnancy. Clin Perinatol 1983;10:369-382.

Sherard GB 3rd, Hodson CA, Williams HJ, et al. Ad.nexal masses and pregnancy: a 12 year experience. Am J Obstet Gynecol. 2003; 189: 358 -363.

6 Bromley B, Benacerraf B. Adnexal masses during pregnancy: accuracy of sonographic diagnosis and outcome. J Ultrasound Med. 1997; 16: 447 -452.

7. Kobayashi F,Sagawa N, Nakamura K et al. Mechanism and clinical significance of elevated CA 125 levels in the sera of pregnant women.Am $J$ Obstet Gynecol 1989;160:563-566

8. Whitecar P, Turner S, Higby K. Adnexal masses in pregnancy: a review of 130 cases undergoing surgical management. Am J Obstet Gynecol. 1999; 181: $19-24$.

9. Novak ER, Lambrou CD, Woodruff JD. Ovarian tumours in pregnancy, An ovarian tumour registry review. Obstet Gynecol 1975;46:401-406.

10. Leiserowitz GS, Xing G, Cress R, Brahmbhatt B, Dalrymple JL, Smith LH. Adnexal masses in preg. nancy: how often are they malignant? Gynecol Oncol. 2006;101:315-321.

11. Reedy MB, Källén B, Kuehl TJ. Laparoscopy during pregnancy: a study of five fetal outcome parameters with use of the Swedish health registry. Am J Obstet Gynecol. 1997; 177: 673 -679.

12. Schilder JM, Thompson AM, DePriest PD, et al. Outcome of reproductive age women with stage IA or IC invasive epithelial ovarian cancer treated with fertility-sparing therapy. Gynecol Oncol. 2002; 87: 1 -7 .

13. Tangir J, Zelterman D, Ma W, Schwartz PE. Reproductive function after conservative surgery and chemotherapy for malignant germ cell tumours of the ovary. Obstet Gynecol. 2003; 101: $251-257$.

14. Christman JE, Teng NN,Lebovic GS, Sikic BI Delivery of normal infant following Cisplatin, Vinblastin, and Bleomycin $(P V B)$ Chemotherapy for malignant teratoma of the ovary during pregnancy.Gynecol Oncol 1990;37:292-295.

15. King LA, Nevin PC, William pp, Carson LF.Treatment of advanced epithelial ovarian carcinoma in pregnancywith Cisplatin-based chemotherapy.Gynecol Oncol 1991;41:78-80.

16. Ferrandina $G$, Distefano $M$, Testa $A$, De Vincenzo $R$, Scambia G. Management of an advanced ovarian cancer at 15 weeks of gestation: case report and literature review. Gynecol Oncol. 2005; 97: 693 -696. 